\title{
Ion Exchange Softening and Alkalization Treatment for Zerodischarge of Circulating Cooling Water
}

\author{
Huiming Zeng ${ }^{1}$, Jiuyang Lin ${ }^{1 *}$, Chunsong Ye ${ }^{1}$, Lihui Tong ${ }^{1}$, Xiaolan Chen ${ }^{1}$, Fei Yu ${ }^{1}$ \\ ${ }^{1}$ School of Power and Mechanical Engineering, Wuhan University, Wuhan, China, ${ }^{*}$ Corresponding author. \\ Email: linjiuyang@126.com
}

Received January $8^{\text {th }}, 2009$; revised January $31^{\text {st }}, 2009$; accepted February $20^{\text {th }}, 2009$.

\begin{abstract}
In order to solve the problems including pipe corrosion, scaling and microbial growth, which severely threat safe operation of circulating cooling water system, this paper proposes ion exchange softening and alkalization process to solve these problems and carries out a series of studies to study the feasibility of ion exchange softening and alkalization process in the simulation process of circulating cooling water system. The studies include product water quality of ion exchange softening and alkalization process, effect on the performance of carbon steel and brass, and the inhibition that suppresses microbial growth. The results indicate that ion exchange softening and alkalization process is feasible to prevent the circulating cooling water system from scaling, pipe corrosion, and microbial growth without any other chemicals. Thus circulating cooling water system can achieve zerodischarge of wastewater.
\end{abstract}

Keywords: Ion Exchange Softening and Alkalization, Circulating Cooling Water, Zerodischarge

\section{Introduction}

Circulating cooling water system is widely used in industrial process and central air conditioning system because of its high water conversation efficiency and rejection of thermal pollution of receiving water compared to oncethrough cooling water system [1]. However, circulating cooling water system has three major problems including pipe corrosion, scaling and microbial growth.

Generally speaking, the general method to solve the three problems is to add chemicals such as scale inhibitor, corrosion inhibitor, and microorganism inhibitors, which can effectively control pipe corrosion, scaling and microbial growth to the circulating cooling water, but the prevalent method brings some disadvantages including the discharge and disposal of harmful chemicals and high operation cost. Currently the researches on developing the environment-friendly chemicals with synergistic effects and high efficiency become a hotspot $[2,3]$. At the same time, the physical methods such as high frequency electromagnetic, electrostatic, and ultrasonic treatment, are also developing. However, neither chemical methods nor physical methods can absolutely solve these problems without any harmful impact on the water environment.

In order to solve these tough problems, this paper puts forward an innovative process, ion exchange softening and alkalization process, to transform the hardness and the corrosive anions into sodium bicarbonate to maintain the $\mathrm{pH}$ value of sodium bicarbonate solution in the fixed range and protect the circulating cooling water system from scaling, pipe corrosion and microbial growth.

\section{Principle of Ion Exchange Softening and Alkalization Process}

\subsection{Discription of Ion Exchange Softening and Alkalization Process for Circulating Cooling Water System}

Figure 1 shows the schematic diagram of the facility for circulating cooling water system consisting of ion exchange system, a circulating water loop and a cooling tower. Ion exchange softening and alkalization process is used for circulating cooling water softening and alkalization treatment. Sodium form strong acidic resin and bicarbonate form strong basic resin are used to remove the hardness and corrosive anions including sulfate and chloride, transform the ions into sodium bicarbonate, and alkalinize product water of ion exchanger. The circulating loop and cooling tower are used to simulate the operation of circulating cooling water system.

\subsection{Ion Exchange Softening and Alkalization System}

Ion exchange softening and alkalization process uses ion exchange resin as a method for water softening and alkalization treatment. During the ion exchange process, strong acidic sodium form ion exchange resin is used as softener to remove divalent cations, especially hardness including calcium ion and magnesium ion. Then the effluent of the cation exchanger in sodium form passes through the anion exchanger in bicarbonate form, so the effluent of ion exchanger mainly contains sodium ion, 
bicarbonate ion and the other ions including calcium ion, magnesium ion, chloride ion, sulfate ion are trace. The general bicarbonate-chloride anion exchange reaction and sodium-calcium or sodium-magnesium cation exchange reaction are shown below.

$$
\begin{aligned}
& 2 \mathrm{RNa}+\mathrm{Ca}^{2+} \rightarrow \mathrm{R}_{2} \mathrm{Ca}+2 \mathrm{Na}^{+} \\
& 2 \mathrm{RNa}+\mathrm{Mg}^{2+} \rightarrow \mathrm{R}_{2} \mathrm{Mg}+2 \mathrm{Na}^{+} \\
& \mathrm{RHCO}_{3}+\mathrm{Cl}^{-} \rightarrow \mathrm{RCl}+\mathrm{HCO}_{3}^{-}
\end{aligned}
$$

\subsection{The Open Equilibrium State of Carbonation Solution}

In circulating cooling water system, circulating cooling water exchanges heat with the atmosphere in cooling tower and it is vaporized partly and concentrated. Carbon dioxide gas in the atmosphere contacts with cooling water fully. When concentration of dissolved carbon dioxide is in line with Henry's law which is applicable to carbon dioxide equilibrium between atmosphere and liquid, the aqueous and atmosphere phases reach the equilibrium state after the spray cooling process in the cooling tower, Henry's law is expressed in Equation 4.

$$
C_{\mathrm{CO}_{2}}=K_{\mathrm{H}} \cdot P_{\mathrm{CO}_{2}}
$$

The carbonate system controls the $\mathrm{pH}$ value of solution. The chemical species of solution that compose the carbonate system include gaseous carbon dioxide, aqueous carbon dioxide, carbonic acid, bicarbonate and carbonate. The presence of carbonate, bicarbonate, and hydroxyl ions accounts for essentially all of the alkalinity, so the alkalinity greatly influences the equilibrium $\mathrm{pH}$ value of the carbonate solution. The relation between equilibrium $\mathrm{pH}$ value in theory and total alkalinity in solution is expressed in Equation 5.

$$
\mathrm{pH}=-\lg \frac{\left(K_{\mathrm{w}}+C_{\mathrm{CO}_{2}} \cdot K_{1}\right)+\sqrt{\left(K_{\mathrm{w}}+C_{\mathrm{CO}_{2}} \cdot K_{1}\right)^{2}+8 \cdot B \cdot C_{\mathrm{CO}_{2}} \cdot K_{1} \cdot K_{2}}}{2 \cdot B}
$$

The equilibrium $\mathrm{pH}$ values of the solutions with different alkalinities at different temperatures are showed in Figure 2. Figure 2 indicates that the equilibrium $\mathrm{pH}$ value of solutions rises as the alkalinity and temperature rise.

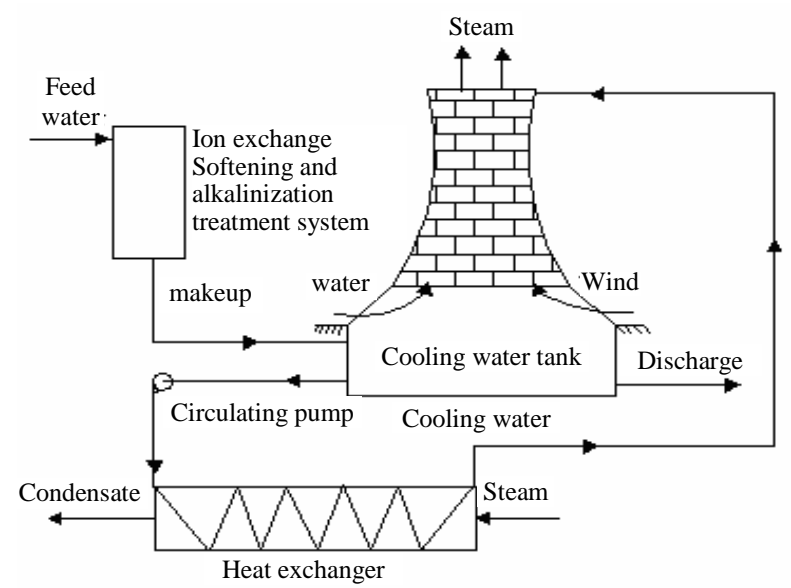

Figure 1. Schematic of ion exchange softening and alkalization for circulating cooling water system

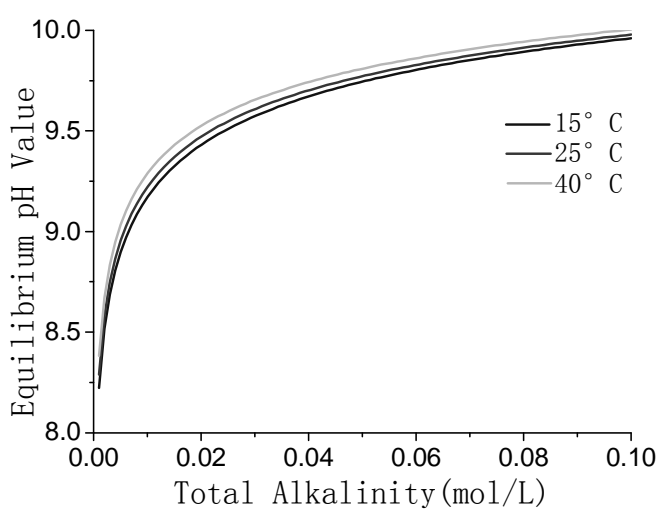

Figure 2. The relation between $\mathrm{pH}$ value and total alkalinity

\subsection{Principle of Anti-Scale Corrosion Inhibition and Suppression of Microbial Growth}

Ion exchange softening and alkalization process removes the hardness mainly including calcium ion and magnesium ion, and the corrosive anions such as sulfate and chloride, transforms the ions into sodium bicarbonate and maintains the $\mathrm{pH}$ value of sodium bicarbonate solution in the fixed range, so the process can effectively prevent the circulating cooling water system from scaling. From the Pourbaix diagram, we can learn that iron and copper can form a passive and compact oxide coating on the surface of metal pipe in the $\mathrm{pH}$ value range from 8.9 to 13.0 and from 8.6 to 10.0, respectively. And for copper pipe, it can form a protective passive coating in the optimal $\mathrm{pH}$ value range from 7.60 to 8.95 at low conductivity [4]. So it's possible to control the $\mathrm{pH}$ value of solution to prevent the metal from corrosion.

To continue to grow properly, an organism in the circulating cooling water must have a source of carbon and energy. In addition, elements such as nitrogen, phosphorus, and trace elements including sulfur, potassium, calcium, and magnesium must be available. Ion exchange softening and alkalization process cuts off the nutrition sources such as nitrogen and phosphorus which are essential for cell synthesis of microorganism. So, the ion exchange process can suppress microbial growth for circulating cooling water system.

\section{Experimental Studies}

\subsection{Effluent Quality of Ion Exchange Softening and Alkalization Process}

The raw water which comes from Yangtze River in China firstly passes through strong acidic sodium form ion exchange resin for softening to remove the hardness, and then the effluent of the cation exchanger in sodium form passes through the anion exchanger in bicarbonate form for the removal of corrosive anions such as sulfate and chloride. The qualities analysises of the raw water and effluent of ion exchanger are shown in Table 1. Table 1 indicates that the ion exchange process can removes all of the hardness and corrosive anions and transforms the ions into sodium bicarbonate. However, the $\mathrm{pH}$ value falls from 7.5 to 6.8 . 


\subsection{Test Results of Carbonate Equilibrium}

The equilibrium $\mathrm{pH}$ value of bicarbonate solution is influenced by the total alkalinity of solution, and the equilibrium $\mathrm{pH}$ value of solution rises as the alkalinity rises, so it is feasible to control the $\mathrm{pH}$ value by adjusting the alkalinity of solution. The relation between theoretical and measured equilibrium $\mathrm{pH}$ value in different alkalinities is showed in Figure 3. Figure 3 illustrates that the measured $\mathrm{pH}$ value approximates to the theoretical equilibrium $\mathrm{pH}$ value. Therefore, the carbonate solution is able to obtain gas-liquid equilibrium state.

\subsection{Pilot Test of Circulating Cooling Water System}

The pilot test flow sheet of ion exchange softening and alkalization treatment tor circulating cooling water system are illustrated in Figure 4. In the study of circulating cooling water system, part of circulating water after ion exchange softening and alkalization treatment sprays, the other part of circulating cooling water goes back to cooling water tank by bypass. In the circulating cooling water system, when the cooling water sprays and contacts with

Table 1. Quality analysis of the raw water and effluent

\begin{tabular}{lcccccc}
\hline Items & $\begin{array}{c}\mathrm{Ca}^{2+} \\
(\mathrm{mol} / \mathrm{L})\end{array}$ & $\begin{array}{c}\mathrm{Mg}^{2+} \\
(\mathrm{mol} / \mathrm{L})\end{array}$ & $\begin{array}{c}\mathrm{Na}^{+} \\
(\mathrm{mol} / \mathrm{L})\end{array}$ & $\begin{array}{c}\mathrm{Cl}^{-} \\
(\mathrm{mol} / \mathrm{L})\end{array}$ & $\begin{array}{c}\mathrm{SO}_{4}{ }^{2-} \\
(\mathrm{mol} / \mathrm{L})\end{array}$ & $\begin{array}{c}\mathrm{HCO}_{3}{ }^{-} \\
(\mathrm{mol} / \mathrm{L})\end{array}$ \\
\hline Raw Water & $9.1 \mathrm{E}-4$ & $3.5 \mathrm{E}-4$ & $7.1 \mathrm{E}-4$ & $5.2 \mathrm{E}-4$ & $4.1 \mathrm{E}-4$ & $2.0 \mathrm{E}-3$ \\
Effluent & 0 & 0 & $3.3 \mathrm{E}-4$ & 0 & 0 & $3.3 \mathrm{E}-3$ \\
\hline
\end{tabular}

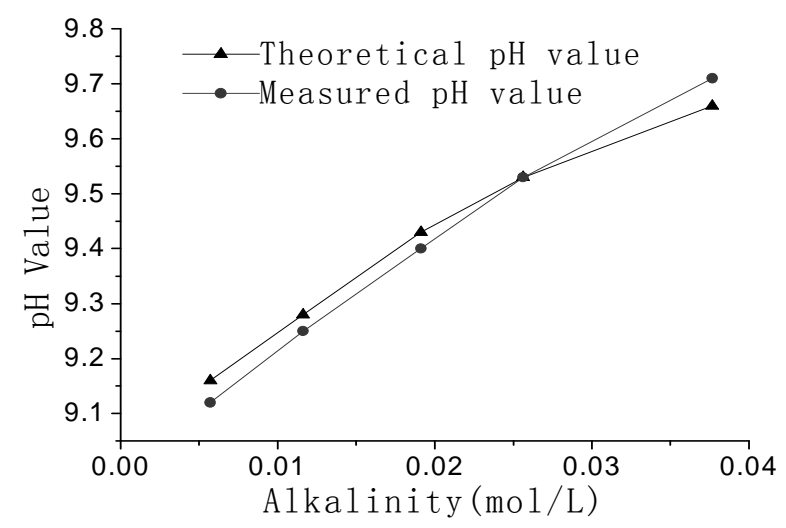

Figure 3. The comparison of measured $\mathrm{pH}$ value and theoretical pH value in different alkalinity

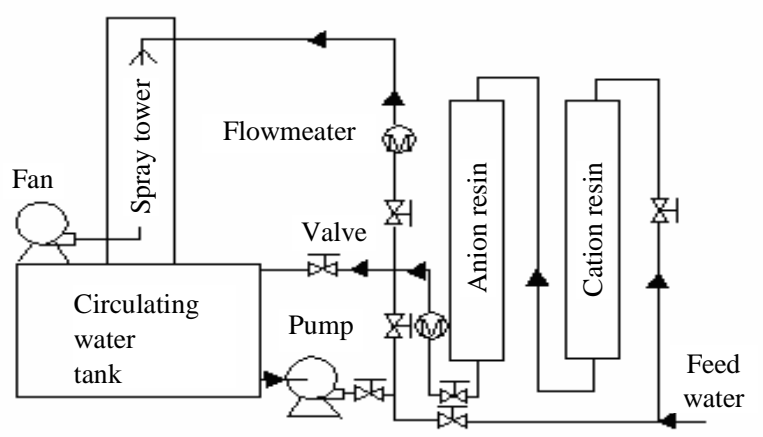

Figure 4. Schematic of the assimilation of circulating cooling water system carbon dioxide gas in the atmosphere fully, the $\mathrm{pH}$ value of cooling water is increasing until carbonate solution obtains the gas-liquid equilibrium. The relation between concentration of hydrogen ion of circulating cooling water and the duration, $T$, of aeration is showed in Equation 6.

$$
\begin{aligned}
& T=-\frac{V}{Q} \cdot\left\{\ln \left(1-\frac{(C-D) \cdot Q \cdot K_{\mathrm{G}}}{\left(\frac{C}{K_{\mathrm{H}} \cdot 55.56}-P_{\mathrm{CO}_{2}}\right) \cdot A}\right\}\right. \\
& C=\frac{B \cdot\left[\mathrm{H}_{\mathrm{i}}^{+}\right]^{2}-K_{\mathrm{w}} \cdot\left[\mathrm{H}_{\mathrm{i}}^{+}\right]}{2 \cdot K_{1} \cdot K_{2}+K_{1} \cdot\left[\mathrm{H}_{\mathrm{i}}^{+}\right]} \\
& D=\frac{B \cdot\left[\mathrm{H}^{+}\right]^{2}-K_{\mathrm{w}} \cdot\left[\mathrm{H}^{+}\right]}{2 \cdot K_{1} \cdot K_{2}+K_{1} \cdot\left[\mathrm{H}^{+}\right]}
\end{aligned}
$$

The variation trends of the measured $\mathrm{pH}$ value of circulating water are showed in Figure 5. Figure 5 indicates that the value of circulating water rises as the duration of aeration increases, and measured $\mathrm{pH}$ value shows the same variation tends as the theoretical value. When the spray flow rate is $400 \mathrm{~L} / \mathrm{h}$ and the volume of circulating water is $175.6 \mathrm{~L}$. It takes 2 hour for the circulating water to keep $\mathrm{pH}$ value stable regardless of the initial $\mathrm{pH}$ value and total alkalinity of circulating water. So for an open circulating cooling water system, the $\mathrm{pH}$ value can be controlled accurately, it takes the fixed time for circulating water to maintain the $\mathrm{pH}$ value stable, and the theoretical mathematic model can be adopted to predict the $\mathrm{pH}$ value of circulating cooling water system.

\subsection{Corrosion Test of Iron and Brass in Open Carbonate Equilibrium System}

In order to studies anti-corrosion performance of carbon steel and brass in equilibrium carbonate solution with different alkalinities, the corrosion tests are carried out. During the tests, static weight loss measurement and

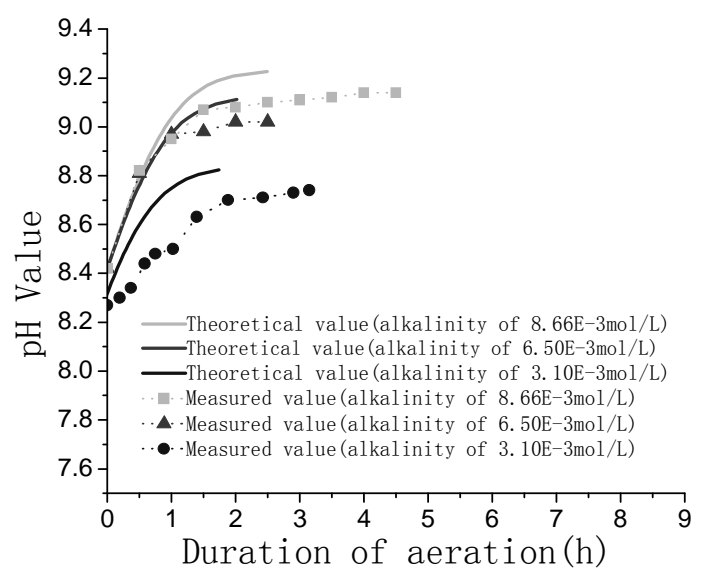

Table 5. Tendency of the variation of the $\mathrm{pH}$ value of solution 
electrochemical methods including polarization curve and Electrochemical Impedance Spectroscopy (EIS) are adopted. In order to study the performance of passive coating formation of brass, the kinetics experiments of passive coating formation are conducted. Figure 6 shows the corrosion rate of brass by weight loss measurement. Figure 7 illustrates the corrosion current density of carbon steel and brass in carbonate solution with different alkalinities. Figure 8 shows Nyquist Plots of carbon steel in carbonate solution with different alkalinities. Figure 9 and Figure 10 show Bode Plots and Nyquist Plots of kinetics of passive coating formation of brass, respectively.

Figure 6 indicates that corrosion rate of brass in bicarbonate solution with different alkalinities is below 5.0E-3 $\mathrm{mm} / \mathrm{a}$, and it means that the bicarbonate solution has good performance on corrosion inhibition. Figure 7 indicates that the corrosion current density of brass rises as the alkalinity of bicarbonate solution rises when the alkalinity is below $3.0 \mathrm{E}-2 \mathrm{~mol} / \mathrm{L}$, and brass has the lowest corrosion current rate when the alkalinity is $3.0 \mathrm{E}-2 \mathrm{~mol} / \mathrm{L}$. Figure 7 and Figure 8 show the same result that when the alkalinity of carbonate solution is $3.0 \mathrm{E}-2 \mathrm{~mol} / \mathrm{L}$, carbon steel has the lowest corrosion current density. Figure 9 and Figure 10 illustrate that firstly the surface of brass forms the compact oxide coating consisting of cuprous oxide, and then the cuprous oxide is transformed into copper oxide by oxidation, when the oxide coating consisting of cuprous oxide forms, it can maintain stable and prevent the brass from corrosion.

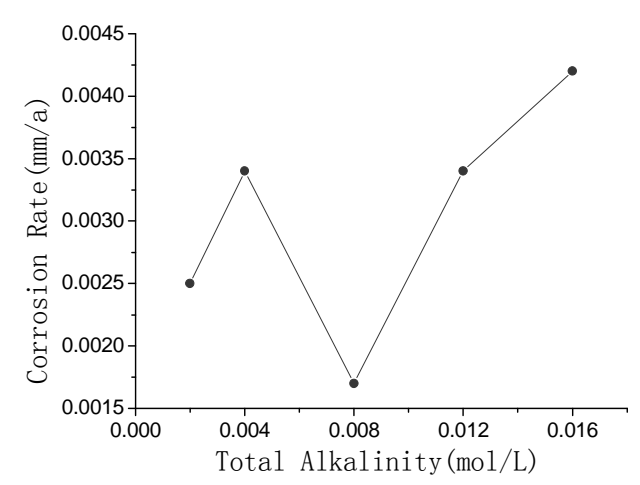

Figure 6. Corrosion rate of brass in bicarbonate solution with different alkalinities

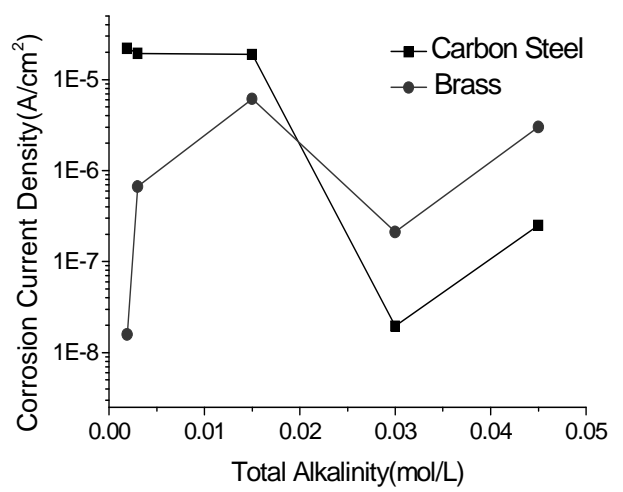

Figure 7. Corrosion current density of carbon steel and brass in bicarbonate solution with different alkalinities

\subsection{Microbial Growth Test}

Ion exchange softening and alkalization process can remove calcium ion, magnesium ion, trace elements and other nutrition resource such as inorganic nitrogen and phosphorus which are essential for microbial growth. However, the circulating cooling water after softening and alkalization treatment provides carbon resource for the microorganism. So it is necessary to study the influence factors of microorganism.

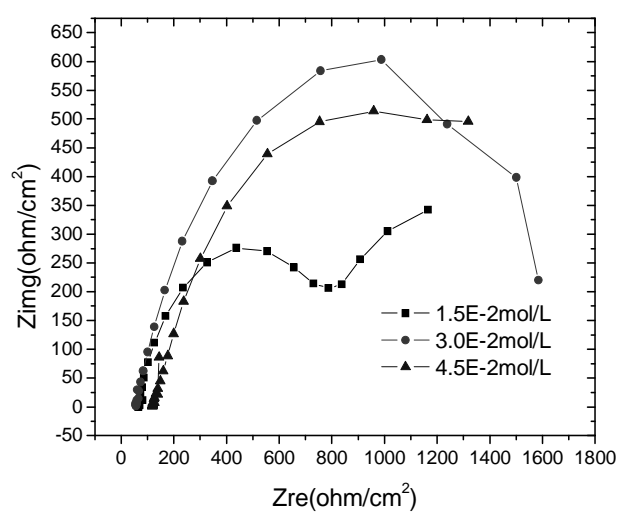

Figure 8. Nyquist plots of carbon steel in carbonate solution with different alkalinities

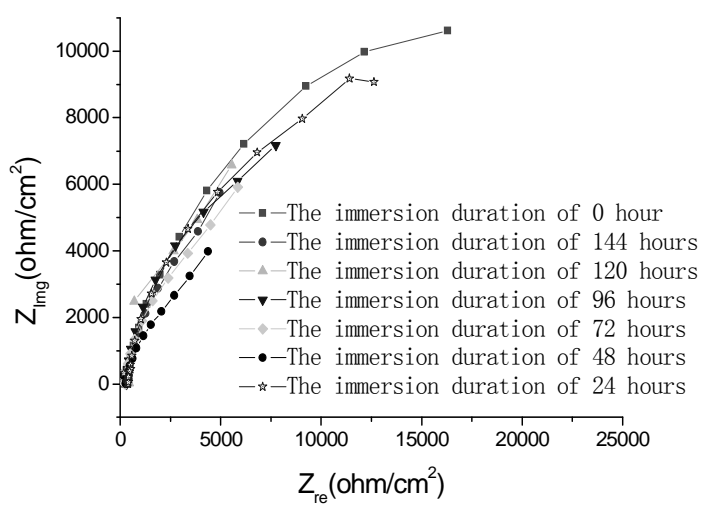

Figure 9. Nyquist Plots of kinetics of passive coating formation of brass in bicarbonate solution with different alkalinities

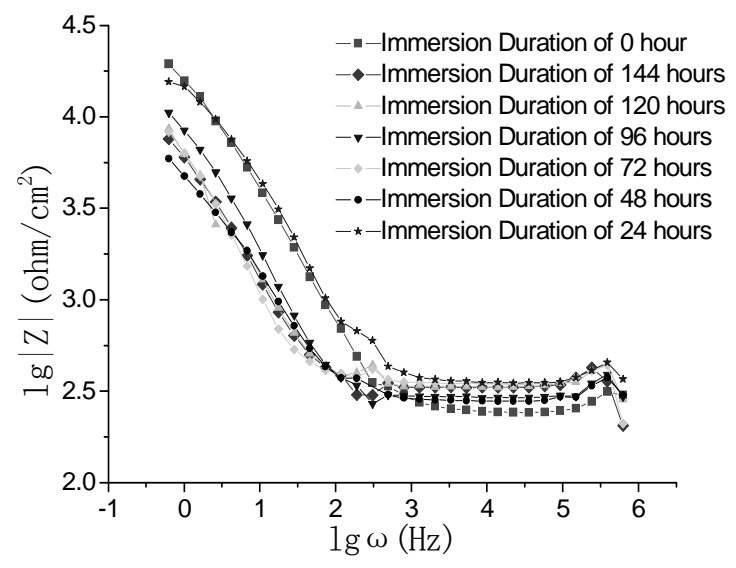

Figure 10. Bode plots of carbon steel in bicarbonate solution with different alkalinities 
Table 2. Microbial growth test in different conditions

\begin{tabular}{|c|c|c|c|c|c|c|c|c|}
\hline Number & $\begin{array}{l}\text { Alkalinity } \\
(\mathrm{mol} / \mathrm{L})\end{array}$ & $\begin{array}{c}\text { Glucose } \\
(\mathrm{g} / \mathrm{L})\end{array}$ & $\begin{array}{c}\text { Protein } \\
(\mathrm{g} / \mathrm{L})\end{array}$ & $\begin{array}{c}\mathrm{NH}_{4} \mathrm{Cl} \\
(\mathrm{g} / \mathrm{L})\end{array}$ & $\begin{array}{c}\mathrm{K}_{2} \mathrm{HPO}_{4} \\
(\mathrm{~g} / \mathrm{L})\end{array}$ & $\begin{array}{c}\mathrm{CaCl}_{2} \\
(\mathrm{~g} / \mathrm{L})\end{array}$ & Multiple of microbial growth & $\begin{array}{l}\text { Decrement of } \\
\operatorname{COD}_{\mathrm{Cr}}(\mathrm{mg} / \mathrm{L})\end{array}$ \\
\hline 1 & 3.3 & 10 & 5 & 0 & 1 & & 10.76 & 1840 \\
\hline 2 & 16.5 & 10 & 5 & 0 & 1 & 0 & 18.34 & 3600 \\
\hline 3 & 33.0 & 10 & 5 & 0 & 1 & 0 & 14.94 & 4800 \\
\hline 4 & 49.5 & 10 & 5 & 0 & 1 & 0 & 13.34 & 8160 \\
\hline 5 & 16.5 & 10 & 0 & 3 & 1 & 0 & 3.27 & 1680 \\
\hline 6 & 16.5 & 10 & 0 & 0 & 0 & 0 & 5.87 & 1440 \\
\hline 7 & 16.5 & 0 & 5 & 0 & 1 & 0 & 6.25 & 1920 \\
\hline 8 & 16.5 & 5 & 0 & 3 & 1 & 0 & 6.02 & 1520 \\
\hline 9 & 16.5 & 0 & 0 & 3 & 1 & 0 & 0.71 & 880 \\
\hline 10 & 16.5 & 10 & 5 & 0 & 1 & 1.5 & 24.33 & 6720 \\
\hline 11 & 16.5 & 10 & 5 & 0 & 1 & 3.0 & 17.48 & 6080 \\
\hline
\end{tabular}

\begin{tabular}{ll}
\hline Nomenclature \\
$C_{\mathrm{CO}_{2}}$ & concentration of $\mathrm{CO}_{2}$ in carbonate solution, mol/L \\
$K_{\mathrm{w}}$ & equilibrium constant for water \\
$K_{1}$ & coefficient of first order dissociation of $\mathrm{H}_{2} \mathrm{CO}_{3}$ \\
$K_{2}$ & coefficient of second order dissociation of $\mathrm{H}_{2} \mathrm{CO}_{3}$ \\
$K_{\mathrm{H}}$ & Henry coefficient, atm \\
-1
\end{tabular}

The test studies the factors including alkalinity, nitrogen, phosphorus, hardness, organic matter. Table 2 shows the test results of the microbial growth test.

Table 2 illustrates that organic matter is the main factor that controls the microbial growth, and the absence of calcium ion, magnesium ion, nitrogen, phosphorus also can suppress the microbial growth. Content of inorganic carbon has no obvious effect on microbial growth.

\section{Conclusions}

Ion exchange softening and alkalization process can remove hardness and corrosive anions dissolved in circulating cooling water, transform all the ions into sodium bicarbonate, and alkalize the circulating cooling water.. So the process can effectively prevent the circulating cooling water system from scaling.

The $\mathrm{pH}$ value of circulating water after spraying can greatly approximate to the theoretical value. Corrosion test illustrates that carbon steel and brass can reach the lowest corrosion rate in the bicarbonate solution with total alkalinity of $3.0 \mathrm{E}-2 \mathrm{~mol} / \mathrm{L}$. To optimize the operation condition of circulating cooling water system and maintain the alkalinity of circulating cooling water is an crucial way to prevent the circulating cooling water system from corrosion. And maintain the alkalinity of carbonate solution in the level of $3.0 \mathrm{E}-2 \mathrm{~mol} / \mathrm{L}$, the concentration factor of circulating cooling water system can reach up to 15 , ion exchange softening and alkalization process can improve the cooling water usage efficiency.

Microbial growth test indicates that orangic matter is the main factor to influence the microbial growth, and the absence of other nutrition source such as calcium ion, magnesium ion, nitrogen, phosphorus also can affect the microbial growth. And ion exchange softening and alkalization process can remove most of organic matter and maintain the low content of organic matters and effectively suppress the microbial growth.

Therefore, ion exchange softening and alkalization process is a feasible and effective method to solve the problems of pipe corrosion, scaling, and microbial growth, improve usage efficiency of cooling water, achieve zerodischarge of wastewater and converse water resource.

\section{Acknowledgement}

The authors would like to thank the anonymous reviewer for their good suggestions.

\section{REFERENCES}

[1] J. K. Kim and R. Smith, "Cooling water system design," Chemical Engineering Science, Vol. 56, No. 12, pp. 3641-3658, 2001.

[2] F. Ziegler, "State of the art in sorption heat pumping and cooling technologies," International Journal of Refrigeration, Vol. 25, No. 4, pp. 450-459, 2002.

[3] M. Saremi, C. Dehghanian, and M. Mohammadi Sabet, "The effect of molybdate concentration and hydrodynamic effect on mild steel corrosion inhibition in simulated cooling water," Corrosion Science, Vol. 48, No.6, pp. 1404-1412, 2006.

[4] C. S. Ye, J. Zhang, Q. Qian, and S. P. Fan, "Study on the tubo-generator inner cooling water treated by ion-exchange micro-basification," China, Journal of Industrial water treatment, Vol. 6, pp. 17-19, 2004. 